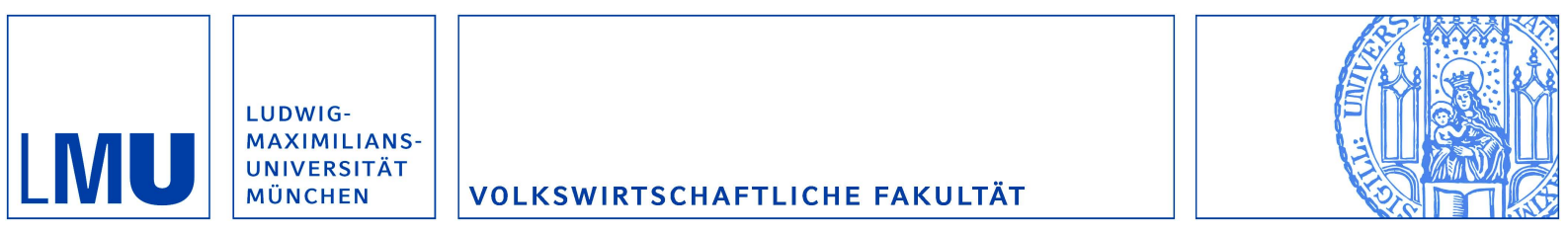

Fahn, Matthias und Rees, Ray:

Household Relational Contracts for Marriage, Fertility and Divorce

Munich Discussion Paper No. 2014-13

Department of Economics

University of Munich

Volkswirtschaftliche Fakultät

Ludwig-Maximilians-Universität München

Online at https://doi.org/10.5282/ubm/epub.20834 


\title{
Household Relational Contracts for Marriage, Fertility and Divorce*
}

\author{
Matthias Fahn† Ray Rees ${ }^{\ddagger}$
}

March 24, 2014

\begin{abstract}
This paper applies the theory of relational contracts to a model in which a couple decides whether to marry or cohabit, how many children to have and subsequently whether to stay together or separate. We make precise the idea that cooperation in a household can be supported by self interest. Since the costs of raising children are unequally distributed between partners and children are a household public good, there is a conflict between individually optimal and efficient, i.e. surplus maximising, decisions. Side-payments are used to support cooperation but are not legally enforceable and thus have to be part of an equilibrium. This requires a stable relationship and credible punishment threats. Within this framework, we analyze the effects of policy variables such as the costs of divorce and post-divorce income payments on the interrelationships among the decisions on marriage, fertility and divorce.
\end{abstract}

Keywords: relational contracts; cohabitation; marriage; fertility; divorce.

JEL Classification: C73, D13, J12, J13, J24.

${ }^{*}$ We thank Patricia Apps, Asnia Asim, Niko Matouschek, and participants at seminars at the University of Munich and Stockholm, the 2009 Annual Conference of the European Association of Law and Economics (Rome), the 2009 Conference of the German Economics Association (Magdeburg), the 2010 Meeting of the American Law and Economics Association (Princeton), the 2010 Workshop on Economics of the Family (ANU,Canberra), the 2011 CESifo Conference on Applied Microeconomics (Munich), and the 2011 Conference on the Economics of the Family (Paris), for many helpful comments on earlier versions of this paper. Remaining errors are our own. Matthias Fahn gratefully acknowledges financial support from the Deutsche Forschungsgemeinschaft through GRK 801.

${ }^{\dagger}$ Corresponding author. Affiliation: University of Munich. Address: Unversity of Munich, Kaulbachstr. 45, 80539 München, Germany. E-mail: matthias.fahn@econ.lmu.de

${ }^{\ddagger}$ Affiliation: University of Munich and University of Warwick. E-mail: Ray.Rees@lrz.uni-muenchen.de 


\section{Introduction}

Over the past four to five decades, fundamental changes have taken place in the nature of the family and the structure of family relationships. ${ }^{1}$ These reflect complex interactions among changes in divorce laws, increasing female labor force participation, innovations in the technology of contraception and changes in social attitudes and norms. This paper is intended to contribute to the economic analysis of these phenomena by constructing a model of a couple-based household which chooses marriage vs cohabitation, its fertility, and whether to continue the relationship or to separate, in the context of given labor market conditions and a set of legal rules regulating post-separation outcomes.

Also over the past four to five decades, there has been substantial development in the economic modelling of the household, and a large theoretical and empirical literature now exists dealing with issues such as marriage, fertility and divorce. A large part of this literature is based on the assumption that family members act cooperatively and necessarily achieve Pareto efficient allocations. $^{2}$ For example, the Nash bargaining models of household behavior originating with Manser and Brown (1980) and McElroy and Horney (1981), or collective choice models (cf. Chiappori [1995] or Browning and Chiappori [1998]), assume that household allocations are Pareto efficient and can somehow be enforced as binding agreements even in a one-shot game. Early challenges to this assumption were made by Ulph (1988), Woolley (1988) and, within the Nash bargaining framework, by Ott (1992), Konrad and Lommerud (1995), Lundberg and Pollak (2003), and Wickelgren (2009), among others. Applying non-cooperative game theory to household decision making in a static environment, they identify sources of inefficient behavior of household members.

In this paper, instead of assuming either cooperative or non-cooperative behavior, we derive conditions for cooperation in a dynamic setting where players are solely driven by their selfinterest and are not able to write exogenously enforceable agreements. Hence, we model the informal agreements between spouses as a relational contract. Generally, relational contracts are agreed arrangements in dynamic games based on actions or outcomes that are observable but not verifiable, i.e., the associated contracts are not legally enforceable but require mutual trust. As agreements in household relationships are to a large extent implicit and extend over quite long periods of time, they present a good subject for an analysis with a relational contracting model. Starting with Bull (1987), relational contracts were initially developed to analyze labor markets and agency situations. MacLeod and Malcomson (1989) provide a complete analysis for perfect information, while Levin (2003) explores the case of imperfect public monitoring. Baker, Gibbons, and Murphy (1994) and Schmidt and Schnitzer (1995) study the interaction between relational and formal contracts. This specifically relates to our model since after a divorce, implicit agreements

\footnotetext{
${ }^{1}$ For extensive documentation and discussion of these changes see in particular the two Symposia on, respectively, Household Economics in the Journal of Economic Perspectives, 2007, 21(2), and Investment in Children in the Journal of Economic Perspectives, 2008, 22(3).

${ }^{2}$ See Apps and Rees (2009), Chapters 3,4 for an extensive survey and list of references.
} 
between partners are typically replaced by formal legal arrangements.

Most closely related to the present paper is the analysis by Matouschek and Rasul (2008). They develop a model where ongoing cooperation within the household creates given benefits and is enforced by punishment threats following deviations. Divorce costs serve as a commitment device and thus increase the ability to generate cooperation. Our model extends this approach and applies it to an analysis of a richer set of phenomena, in particular the fertility decision, which is assumed to be made at relatively early stages of a relationship. The underlying model consists of two riskneutral players, the primary and the second earner (referred to as he and she respectively ${ }^{3}$ ), who form a - potentially - long-lasting relationship. They first decide whether to marry or cohabit and then how many children they want to have. When children are present, the second earner reduces her labor market supply. This causes current income losses as well as a reduced accumulation of human capital, thus inducing lower future wages. At a later stage of the relationship, the couple decides whether to remain together or to separate. Remaining together is efficient if the sum of players' payoff levels within the relationship is higher than outside. Reallocations of resources may be needed to maintain an efficient marriage. One partner might prefer a separation while the other wants to stay together. Then, the former has to be sufficiently compensated.

It is not however possible to make a formally binding commitment to a certain contingent allocation of the utility surplus arising from the relationship ex ante. Therefore, all related promises have to be self-enforcing and part of equilibrium strategies. ${ }^{4}$ Cooperative behavior is only individually rational if reneging is followed by sufficient and credible punishment. A separation as punishment must be credible in the sense that it has be optimal for a player to actually terminate the relationship. In a first step therefore, we derive an enforceability constraint that determines the maximum enforceable fertility level. If this constraint does not bind, fertility is at its efficient level, i.e., maximizes the sum of players' utilities; if it binds, fertility is inefficiently low. The enforceability constraint constitutes the main difference to approaches that simply assume efficiency, as in Nash bargaining or collective models, where such a condition is absent.

After identifying the (constrained) Pareto efficient equilibrium, we analyze the situation following a divorce in more detail. While agreements during a relationship are to a large extent implicit, this changes after a divorce. When all goodwill is lost, issues like monetary transfers between former spouses are mainly governed by law. Thus, we take an institutional perspective and use our setup to analyze the impact of some specific policy changes on fertility, marriage stability, and the propensity to get married versus cohabiting. In doing so, we want to contribute to the discussion concerning low birth rates in many countries. We argue that in addition to issues that deal with the increased opportunity costs of children, a shift in the enforceability of transfers induced by legal changes can also be an important factor determining fertility levels, in the short- as well as

\footnotetext{
${ }^{3}$ Reflecting the fact that $70-90 \%$ of second earners in North America and Europe are female. See Immervoll et al., 2009, Table 1, for country-specific numbers.

${ }^{4}$ Although bargaining models might implicitly assume a dynamic setting to support efficient decisions, they do not make precise the conditions necessary for cooperation.
} 
in the long-run.

Part of this analysis deals with divorce costs. Our model predicts that divorce costs may in general have a positive impact on fertility, but only if it is inefficiently low due to a binding enforceability constraint. Then, higher divorce costs increase enforceable transfers by fostering relationship stability and decreasing players' outside option utilities. Hence, a marriage can serve as a commitment device to enforce cooperation within a relationship. This idea has previously been discussed by Becker (1991) and Rowthorn (1999), was more formally derived by Matouschek and Rasul (2008), and empirically tested by various authors (see Rasul [2003], Stevenson [2007], Matouschek and Rasul [2008], and Bellido and Marcén [2011]).

Similarly to Matouschek and Rasul (2008), we show that the increased commitment induced by high divorce costs does not necessarily make the couple better off nor increase their chosen fertility level. Making a divorce more difficult induces couples to stay together when their match quality has become relatively bad and they would prefer to break up in the absence of divorce costs. If the gains from increased commitment are lower than this welfare loss, a couple might not get married in the first place, but instead choose to cohabit (where separation costs are substantially lower). In this way higher divorce costs might ultimately decrease fertility. Which effect dominates depends on whether the enforceability constraint binds and if so, on how much it causes realizable fertility to differ from its efficient level.

In addition, the result that the impact of divorce costs on welfare, i.e. the couple's propensity to marry, is ambigous is in line with empirical results presented by Alesina and Giuliano (2007) who, in contrast to Rasul (2003) and Matouschek and Rasul (2008), find that the introduction of unilateral divorce, which is associated with a reduction of divorce costs, does not imply a decrease but rather an increase in the number of marriages. Concerning the impact on fertility, Alesina and Guiliano (2007) also find that in-wedlock fertility basically remains unaffected by the adoption of unilateral divorce laws, while out-of-wedlock fertility decreases significantly and fertility rates for newly married couples go up. This further supports our view that the impact of divorce costs on marriage and fertility overall is not as obvious as it might seem, and our model is rich enough to capture more aspects of this interaction than just an increased degree of commitment.

Extending Matouschek and Rasul (2008), we show that post-divorce wealth division rules might actually be a more effective instrument to increase fertility than divorce costs. Since, in order to keep the model relatively simple, we do not have saving and therefore wealth creation by a couple, we model these in the form of a simple rule providing for post-separation income transfers from the primary to the second earner. Since they are purely redistributive, such payments have no impact on relationship stability and hence do not have the potentially negative consequences of divorce costs. Fertility can be increased, however, because the payments serve as a partial insurance against the human capital loss the spouse responsible for child care suffers. Both effects together no direct impact on relationship stability in equilibrium combined with an increased slackness of the enforceability constraint - increase the relative benefits of being married compared to cohabiting 
for higher post-separation payments.

Finally, we show that if the second earner's marginal opportunity costs of having children are high, the couple should be more inclined to marry if they want to have children. Indeed, McLanahan (2004) and Lundberg and Pollak (2007) find that mothers with college education where human capital accumulation at early stages of a career has a relatively large impact on future earning prospects - still mostly have their children within a marriage, whereas nonmarital childbearing has substantially increased for mothers with lower levels of education.

Note that we do not impose any assumption related to social norms, except that the secondary earnier is made wholly responsible for child-rearing. Though not literally true - primary earners frequently share some of the task - it still captures the important implication of the actual relative degree of specialization in many households, that this creates the need for implicit intra-household exchanges to which spouses cannot formally commit. All other, especially marriage related, norms are excluded. Thus, our model mostly reflects households in societies where the importance of social norms related to marriage has declined. As Lundberg and Pollak (2007) state, many - especially Western - societies have changed in the past decades, and in particular the stigma associated with cohabitation or nonmarital childbearing has almost disappeared. If norms become less important, a couple will only marry if the institutional setting associated with marriage gives them sufficiently large benefits relative to the costs. That is the starting point of our analysis.

\section{The Model}

Two individuals decide whether to form a household and, if so, whether to marry or cohabit. In each case a household consists of a primary and a second earner, denoted $i=1,2$. There are two periods, $t=1,2$, and players discount the future with the factor $\delta>0 .{ }^{5}$ The periods $t=1$ and $t=2$ differ with respect to the players' action sets. In $t=1$, the couple decides about the institutional setting of their relationship - whether they marry or cohabit - and the number of children they want to have. In $t=2$, the couple decides whether to remain together or separate. Transfers to redistribute income are possible in both periods.

Formally, at the beginning of $t=1$, the couple selects $m \in\{0,1\}$, where $m=1$ describes a marriage and $m=0$ cohabitation. Obviously, a marriage must be a unanimous decision. Afterwards, the couple chooses to have $n$ children, with $0 \leq n \leq \bar{n}$, where we assume $n$ is a real number. This requires the second earner to devote $c(n)$ of her total time allocation (normalized to 1) to raising children in $t=1$, with $c(0)=0, c^{\prime}>0, c^{\prime \prime} \geq 0^{6}$ and $c(\bar{n}) \leq 1$. In this period therefore she earns $(1-c(n)) w_{21}$, where $w_{21}$ is her first-period wage. In the second period, the second earner supplies

\footnotetext{
${ }^{5}$ We do not restrict $\delta$ to be smaller than 1 , since it does not only reflect time preferences, but can also relate to the relative weight players attach to consumption in the second period.

${ }^{6}$ Note that the assumption that $c^{\prime \prime}$ is positive is not necessary for our results, as long as - if negative - it would still be sufficiently large to keep second order conditions satisfied.
} 
her total time allocation of 1 to the labor market, earning $w_{22}(n) \geq 0$. Because of work-related human capital acquisition, the wage is an increasing concave function of her period 0 labor supply and therefore a decreasing concave function of fertility, i.e. $w_{22}^{\prime}<0$ and $w_{22}^{\prime \prime} \leq 0$.

The primary earner works full time in every period. As his human capital accumulation is of no interest to our analysis, his wage $w_{1}$ is constant over time. Furthermore, we assume that $w_{1} \geq w_{22}(0)>w_{21}$. At the end of period $t=1$, a payment $p_{1} \gtreqless 0$ can be made from one partner to the other. If $p_{1}>0$, the primary earner makes the payment.

The timing in period $t=1$ is summarized in the following graph:

\begin{tabular}{cccccc}
\hline$t=1$ & Couple selects & $n$ is & Spouses & Transfer & $t=2$ \\
& $m \in\{0,1\}$ & chosen & work, earn & $p_{1}$ is made & \\
& & income & &
\end{tabular}

The spouses' utilities in period $t=1$ are

$$
u_{i 1}(n)=x_{i 1}+\varphi_{i}(n)
$$

with $\varphi_{i}(0)=0, \varphi_{i}^{\prime}>0$ and $\varphi_{i}^{\prime \prime}<0$ for $i=1,2,{ }^{7}$ where $x$ is a private consumption good. Individual consumption is defined by

$$
\begin{gathered}
x_{11}=w_{1}-p_{1} \\
x_{21}=w_{21}[1-c(n)]+p_{1} .
\end{gathered}
$$

In period $t=2$, both partners work and receive their wages, $w_{1}$ or $w_{2}(n)$, respectively. In addition, they decide whether to separate or stay together and can make transfers. Then, equilibrium utilities in the second period given the couple is still together are

$$
u_{i 2}^{*}(n)=x_{i 2}+\varphi_{i}(n)+R .
$$

$R$ is the couple's relationship capital which each of the partners enjoys within the relationship as long as no one of them has taken out-of-equilibrium actions (what exactly is meant by this is described in section 3 below). $R$ reflects the common assumption that the couple receives utility just by being together and is identical for marriage and cohabitation. The assumption that $R$ is zero in period $t=1$ is solely made for simplicity and without loss of generality.

\footnotetext{
${ }^{7}$ In addition, we impose the purely technical assumption (making sure the second order conditions in the respective maximization problems are satisfied) that $-w_{20} c^{\prime \prime}+\varphi_{2}^{\prime \prime} \leq 0$ for all $n$. Since $\varphi_{2}^{\prime \prime}<0$ this allows both increasing and decreasing returns, $c^{\prime \prime} \gtreqless 0$.
} 
The $x_{i 2}$ are again defined by $x_{12}=w_{1}-p_{2}$ and $x_{22}=w_{22}(n)+p_{2}$, where $p_{2} \gtreqless 0$ is the total net transfer made in period 2. Note that the payment $p_{t}$ need not be explicit, its value is implied by any choice of $n$ and the $x_{i t}$, given $w_{1}, w_{21}$ and $w_{22}(n)$. For analytical purposes however it is useful to treat this as if it were an explicit payment. However, no explicit contract on the $p_{t}$ is feasible, it has to be part of an equilibrium supported by the household relational contract (HRC), defined below.

A separation, on the other hand, has the following consequences:

- Each receives an exogenously given outside utility $\tilde{v}_{i}$, a random variable which reflects possibilities outside the current relationship, such as a potential new relationship. Hence, the difference between $R$ and $v_{i}$ determines the current "match quality" of the couple in a given period. The values $\tilde{v}_{i}$ are drawn independently at the beginning of the second period from a distribution $F\left(\tilde{v}_{i}\right)$ with continuous density $f\left(\tilde{v}_{i}\right)$, strictly positive everywhere on the support $\left[0, v_{i}^{1}\right]$, where $F\left(\tilde{v}_{i}\right)$ is the same for marriage and cohabitation. Furthermore, we denote the unconditional expectation for each partner $E\left[\tilde{v}_{i}\right] \equiv \bar{v}_{i}$. We also assume that both $v_{1}$ and $v_{2}$, are observed by each partner immediately after realization. ${ }^{8}$

If the couple had chosen to marry, as opposed to cohabiting, a separation is a divorce and has two further effects.

- The partners bear (possibly unequal) divorce costs $k_{i}>0$, which can have monetary as well as non-monetary components.

- The second earner receives a monetary transfer $\phi \cdot\left(w_{1}-w_{22}(n)\right)$, from 1 , with $\phi \leq 0.5$. Although the transfer does not directly depend on the number of children, $n$ enters via its impact on 2's wage. The factor $\phi$ is assumed to be known ex ante and determined by law. Note that $\phi$ implicitly redistributes wealth as measured by future income streams. ${ }^{9}$

Furthermore, no voluntary transfer $p_{2}$ is made if the couple separates. Given the couple separates at the beginning of period $t=2$, the payoffs are

$$
u_{12}^{d}\left(n, v_{1}\right)=w_{1}+\varphi_{1}(n)+v_{1}-\mathbf{1}_{m=1}\left\{\phi \cdot\left(w_{1}-w_{22}(n)\right)+k_{1}\right\}
$$

and

$$
u_{22}^{d}\left(n, v_{2}\right)=w_{22}(n)+\varphi_{2}(n)+\mathbf{1}_{m=1}\left\{\phi \cdot\left(w_{1}-w_{22}(n)\right)-k_{2}\right\}+v_{2},
$$

\footnotetext{
${ }^{8}$ The assumption that spouses know their partners' outside option fairly well is supported by Peters (1986)

${ }^{9}$ Child custody rules are excluded from the analysis in this paper. In an earlier version, Fahn and Rees, 2011, we assumed that custody is granted to the secondary earner and that the primary's earner's access to his children is lower if the relationship ends. Since it is not always clear to what extent custody arrangements differ for married or cohabiting couples, we restrict our focus here to divorce costs and monetary payments as the consequences of a divorce.
} 
where $\mathbf{1}_{m=1}$ is an indicator function including divorce costs and alimony payments if the couple has been married. Thus we model cohabitation as essentially the decision to avoid divorce costs and regulation of monetary payments. Possible costs or payoffs generated by the act of getting married itself (as opposed to cohabiting) are ignored. ${ }^{10}$ Expected values of separation utilities $E\left[u_{i 2}^{d}\left(n, \tilde{v}_{i}\right)\right]=u_{i 2}^{d}\left(n, \bar{v}_{i}\right)$ are denoted $\bar{u}_{i 2}^{d}(n)$.

\section{Household Relational Contracts}

\subsection{Basic Assumptions}

The couple has to decide on the legal form of their relationship, the number of children they want to have, transfers $p_{t}$, and - in the second period - whether they separate or stay together. We assume that at the beginning of period $t=1$ they formulate a household relational contract (HRC), which is a subgame perfect equilibrium of the game and specifies all actions players will take conditional on all possible histories. Thus, players choose strategies that maximize their discounted utility streams in each subgame given their partner's strategy. Note that the HRC cannot be a legally binding contract contingent on actions or outcomes, because of the non-verifiability of the payments $p_{t}{ }^{11}$

For the first period of the game, the HRC specifies $m^{*}$, equilibrium fertility $n^{*}$ and the transfer $p_{1}$. Given equilibrium actions have actually been selected in the first period, we make the following assumption concerning period 2 activities:

Assumption 1: Assume the game is in equilibrium at the beginning of period $t=2$. Then,

- a separation occurs if and only if that is efficient, i.e. if

$$
u_{12}^{d}\left(n^{*}, v_{1}\right)+u_{22}^{d}\left(n^{*}, v_{2}\right)>u_{12}^{*}\left(n^{*}\right)+u_{22}^{*}\left(n^{*}\right)
$$

- given the couple stays together, the resulting net surplus

$$
s_{2}\left(n^{*}, v_{1}, v_{2}\right)=u_{12}^{*}+u_{22}^{*}-\left[u_{12}^{d}\left(n^{*}, v_{1}\right)+u_{22}^{d}\left(n^{*}, v_{2}\right)\right]
$$

is shared in the following way: The primary earner receives $\alpha \in[0,1$,$] , the secondary$ earner $(1-\alpha)$, where $\alpha$ can be chosen arbitrarily as part of the HRC. Hence, $u_{12}^{*}\left(n^{*}\right)=$

\footnotetext{
${ }^{10}$ Note that we abstract from consumption costs of children. If we included such costs and assumed a given allocation among partners, our results would not be affected qualitatively. Neither do we consider child support laws. These are beyond the scope of our analysis, especially as one problem associated with them is that fathers often do not pay despite the existence of a legal obligation (see Allen and Brinig, 2010).

${ }^{11}$ This is supported by the argument that individual consumptions within a household cannot be verifiably measured. In reality of course there is a far richer set of reasons for the impossibility of complete marital contracts than this.
} 


$$
\alpha s_{2}\left(n^{*}, v_{1}, v_{2}\right)+u_{12}^{d}\left(n^{*}, v_{1}\right) \text { and } u_{22}^{*}=(1-\alpha) s_{2}\left(n^{*}, v_{1}, v_{2}\right)+u_{22}^{d}\left(n^{*}, v_{2}\right)
$$

Assumption 1 seems quite strong, given the proclaimed non-verifiability of actions and transfers. However, having the game end after the second period in combination with assumption 1 can be regarded as a reduced version of a fully dynamic game. Consider the following, slightly different, structure of the game: The couple interacts repeatedly in an infinitely repeated game and in all periods $t \geq 2$, a new realization of $\tilde{v}_{i}$ is drawn. Transfers to maintain the relationship have to be self-enforcing, i.e. part of a subgame perfect equilibrium. In addition, transfers and separation decision are not restricted to be made at a specific date within period $t$, but can be made at any time. ${ }^{12}$ In an earlier version of this paper (Fahn and Rees, 2011), we show that this game is analytically equivalent to the one described here.

Finally, we have to specify what happens out of equilibrium, i.e. if the partners fail to reach an agreement at the beginning of $t=1$, or if at any later stage within period 1 , they deviate from the behavior specified by the HRC. This is necessary because if cooperative behavior is against the short-run interest of one player, it can only be sustained if the partner is trusted to also act cooperatively in the future. We model this by assuming that after any deviation in period 1 , there is a complete loss of trust, and so no voluntary transfer will be made in the second period. In addition, the relationship capital of the other partner - the one who was "betrayed" - drops to $\underline{R}<0$. Concerning the size of $\underline{R}$, we impose

Assumption 2: Given one player breaches the relational contracts, the other player's relationship capital drops to $\underline{R}<0$, where $\underline{R}$ is so small that the relationship cannot be sustained anymore, independent of the realization of outside utilities $\tilde{v}_{i}$.

Assumption 2 implies that a deviating player is punished by a separation, ${ }^{13}$ and that the relating punishment threat is always credible. This assumption substantially simplifies the following analysis since reservation utilities are identical to separation utilities. ${ }^{14}$ It can be justified by arguments similar to those presented by Hart and Moore (2008), where deviations from the terms of

\footnotetext{
${ }^{12}$ Wickelgren (2007), among others, also makes the argument that these kinds of decisions should be possible at any point in time.

${ }^{13}$ Abreu (1986) shows that in a repeated game with symmetric information, a deviation should optimally be followed by a reversion to the equilibrium with the lowest payoff for the reneging player. However, in the household Nash bargaining literature discussed in the Introduction, considerable discussion has taken place over whether separation is too drastic a punishment for failure to disagree, and this has led to models which take as threat points non-cooperative Nash equilibria within an ongoing household (or a combination of both - see the "separate spheres" model by Lundberg and Pollak [1993]). It is said, for example, that one would not threaten divorce over a failure to agree on the colour of a sofa. While we agree with that viewpoint, the class of household decisions being analyzed in this paper is we believe sufficiently fundamental that threats based on separation are the appropriate ones to assume.

${ }^{14}$ The possibility that a deviation does not necessarily imply an immediate separation (i.e. the partners temporarily continue in an uncooperative relationship) is analyzed in an earlier version of this paper (Fahn and Rees, 2011).
} 
a (there: explicit) contract can trigger aggrievement costs which are imposed on one's contracting partner.

Finally, if one partner does not agree on equilibrium fertility $n^{*}$ - the fertility level specified by the HRC and supposedly followed by future transfers - the couple gets separated at the end of period $t=1$, without any voluntary transfer being made. In this case, they have $\underline{n}=\min \left\{\underline{n}_{1}, \underline{n}_{2}\right\}$ children, with $\underline{n}_{i} \in \operatorname{argmax} u_{i 1}^{0}+\delta \bar{u}_{i 2}^{d}$, where $u_{i 1}^{0}$ is player $i$ 's period-0 utility given $p_{1}=0 .{ }^{15}$ Generally, we will have $\underline{n}_{1} \neq \underline{n}_{2}$ (since children are a public good and only the second earner engages in childcare), and a Pareto improvement is possible in the sense that the partner with a lower $\underline{n}_{i}$ would be willing to agree on a higher fertility level in exchange for wealth transfers.

This assumption might seem a bit bizarre - why should the couple have kids at all if they are going to split up anyway? However, we merely impose it to keep the formal analysis consistent (recall that subgame perfection requires players to maximize their utilities in each subgame on and off the equilibrium path). Our results would remain qualitatively unaffected if, for example, the couple had no kids at all (i.e. $\underline{n}=0$ ) after a partner is not willing to accept $n^{*}$ anymore.

Our objective is to derive a subgame perfect equilibrium that maximizes the sum of players' expected payoff streams at the beginning of period 1. Compared to a setting where each player receives a fixed share of the resulting surplus, our approach leads to an identical outcome with respect to equilibrium fertility. The marriage decision might be affected by the allocation of the surplus only if no transfers were possible at the beginning of the game.

Using backward induction, we start with the analysis of period 2.

\subsection{Period $t=2$}

In period $t=2$, the partners decide whether to separate or stay together. Given Assumption 1, the couple breaks up if and only if this is efficient, i.e. if $s_{2}\left(n^{*}, v_{1}, v_{2}\right)<0$. This implies that for given parameter values, the occurrence of a separation in equilibrium only depends on the realization of outside utilities $v_{1}$ and $v_{2}$, or more precisely on its sum, independent of the respective individual values. Hence, define

$$
\tilde{v} \equiv \tilde{v}_{1}+\tilde{v}_{2}
$$

where $\tilde{v}$ has distribution $G(\tilde{v})$ and continous density $g(\tilde{v}) \equiv(f * f)(\tilde{v})$ and is strictly positive everywhere on the support $\left[0,2 v^{1}\right]$. Now, we can establish

Lemma 1: A separation takes place if and only if $\tilde{v}>\hat{v}$, with

$$
\hat{v}=2 R+\mathbf{1}_{m=1}\left\{k_{1}+k_{2}\right\}
$$

\footnotetext{
${ }^{15}$ Note that the second order condition is satisfied, since $\frac{d^{2}\left(u_{11}^{0}+\delta \bar{u}_{12}^{d}\right)}{d n^{2}}=\varphi_{1}^{\prime \prime}+\delta\left[\theta \varphi_{1}^{\prime \prime}+\phi \cdot \bar{w}_{2}^{\prime \prime}\right]<0$ and $\frac{d^{2}\left(u_{21}^{0}+\delta \bar{u}_{22}^{d}\right)}{d n^{2}}=-w_{20} c^{\prime \prime}+\varphi_{2}^{\prime \prime}+\delta\left[\bar{w}_{2}^{\prime \prime}(1-\phi)+\varphi_{2}^{\prime \prime}\right]<0$.
} 
Proof: Since the utility of having children, as well as the sum of incomes in the second period is the same within as well as out of the relationship, we have $s_{2}\left(n^{*}, v\right)=2 R+\mathbf{1}_{m=1}\left\{k_{1}+k_{2}\right\}-v$. Setting $s_{2}\left(n^{*}, v\right)=0$ gives $(3)$. Since $s_{2}\left(n^{*}, v\right)$ is decreasing in $v$, a separation is observed for all values of $v$ above $\hat{v}$. Q.E.D.

The probability of a separation is $(1-G(\hat{v}))$. Furthermore, note that $\hat{v}>2 v^{1}$, i.e. a separation is never observed in equilibrium, is possible as well.

\section{Relationship Stability for given $n^{*}$}

The stability of the relationship is an important determinant of the enforceability of cooperation; Lemma 2 captures the impact of divorce laws on this stability, taking $n^{*}$ as given:

Lemma 2: Assume $m=1$. Then, a separation in period 2 is less likely the higher are divorce costs, while it is independent of $\phi$.

Proof: The probability of divorce equals $(1-G(\hat{v}))$ and is decreasing in $\hat{v}$. The proposition thus follows straightforwardly from differentiating $\hat{v}=2 R+k_{1}+k_{2}$, which gives

$$
\frac{d \hat{v}}{d k_{1}}=\frac{d \hat{v}}{d k_{2}}=1 ; \frac{d \hat{v}}{d \phi}=0 .
$$

Q.E.D.

These results are perfectly intuitive. Divorce costs are a form of deadweight loss to the couple, while the post-divorce payments represent a pure redistribution, hence do not affect the efficiency of remaining together.

Furthermore, the results for $k_{i}$ are valid for couples married at the time when there is a change in the law. They do not imply that divorce rates have to go up in the long run if costs are reduced. Instead, a new institutional setting also changes incentives to actually get married, thus affecting subsequent divorce propensities. We further explore this issue in section 5 below. For now, just note that short-run effects in reality do indeed appear to differ from long-run effects: For example, the change to unilateral divorce laws in many US states some decades ago could be regarded as a reduction of divorce costs. ${ }^{16}$ Afterwards, divorce rates went up (see Friedberg [1998]) in the short

\footnotetext{
${ }^{16}$ Then, Becker's (1991) claim that which of these kinds of divorce regimes is in place should have no impact on the likelihood of divorce is violated by construction. Clark (1999) or Wickelgren (2009) derive further mechanisms for how the allocation of property rights can have an impact on divorce probabilities, for example by affecting ex-ante investments.
} 
run. However, they returned essentially to their initial levels after some time (see Wolfers [2006] and Matouschek and Rasul [2008]).

\subsection{Period $t=1$}

We now derive the constraints that specify to what extent a transfer $p_{1}$ is enforceable, taking second-period utility allocations (represented by $\alpha$ ) into account. It turns out that the different conditions can be merged into one constraint, which determines the maximum enforceable fertility level. Denote by $\underline{n}_{i}$ the fertility level that $i$ would most prefer. To focus on the case we think is the most relevant one, we impose

Assumption 3: $\underline{n}_{1}>\underline{n}_{2}$, hence $\underline{n}=\underline{n}_{2}$ in the case of no agreement.

Given that the secondary earner effectively has to bear the costs of having children, this assumption will be satisfied in our model as long as $\varphi_{1}(n)$ is not too much smaller than $\varphi_{2}(n)$. In the first period, suppose that the spouses agree on equilibrium fertility $n^{*}$ and an associated transfer $p_{1}$. It his helpful to define the players' second period payoffs, as expected in period 1. Denote the expected net surplus of remaining together - as opposed to separating - as $\bar{s}_{2}\left(n^{*}\right)$. Since the ex-ante probability of staying together is $G(\hat{v})$, we have $\bar{s}_{2}\left(n^{*}\right)=G(\hat{v}) \mathrm{E}\left[s_{2}\left(n^{*}, v \mid v \leq \hat{v}\right)\right]=$ $G(\hat{v})\left[u_{12}^{*}\left(n^{*}\right)+u_{22}^{*}\left(n^{*}\right)-\left(\bar{u}_{12}^{d}\left(n^{*} \mid v \leq \hat{v}\right)+\bar{u}_{22}^{d}\left(n^{*} \mid v \leq \hat{v}\right)\right)\right]$, where $\bar{u}_{i 2}^{d}\left(n^{*} \mid v>\hat{v}\right)$ is player i's expected separation payoff conditional on $v>\hat{v}$. Hence, in equilibrium players expect to get $\bar{u}_{12}^{*}\left(n^{*}\right)=\alpha \bar{s}_{2}\left(n^{*}\right)+\bar{u}_{12}^{d}\left(n^{*}\right)$ and $\bar{u}_{22}^{*}\left(n^{*}\right)=(1-\alpha) \bar{s}_{2}\left(n^{*}\right)+\bar{u}_{22}^{d}\left(n^{*}\right)$, respectively.

Now, two kinds of conditions have to be satisfied so that $n^{*}$ can actually be part of an equilibrium. First of all, given players believe that the transfer $p_{1}$ is made, it has to be optimal for both to choose $n^{*}$ rather than any other level, i.e. insist on $\underline{n}$. This is captured by incentive compatibility (IC) constraints, which are

(IC1)

$$
w_{1}+\varphi_{1}\left(n^{*}\right)-p_{0}+\delta\left(\alpha \bar{s}_{2}\left(n^{*}\right)+\bar{u}_{12}^{d}\left(n^{*}\right)\right) \geq w_{1}+\varphi_{1}(\underline{n})+\delta \bar{u}_{12}^{d}(\underline{n})
$$

for player 1 , and

$$
w_{21}\left[1-c\left(n^{*}\right)\right]+\varphi_{2}\left(n^{*}\right)+p_{0}+\delta\left((1-\alpha) \bar{s}_{2}\left(n^{*}\right)+\bar{u}_{22}^{d}\left(n^{*}\right)\right) \geq w_{21}[1-c(\underline{n})]+\varphi_{2}(\underline{n})+\delta \bar{u}_{22}^{d}(\underline{n})
$$

for the second player.

Furthermore, it has to be in the interest of the players to make a promised transfer after equilibrium fertility $n^{*}$ has been realized. This is only the case if reneging triggers a sufficient punishment. As discussed above, this punishment takes the form of forcing a player down to their reservation utility and induces a separation (Assumption 2). The following dynamic enforcement 
(DE) constraints make these arguments precise. If a transfer is positive, the primary earner has to decide whether to make it or renege. He will only keep his promise, if

(DE1)

$$
p_{1} \leq \delta \alpha \bar{s}_{2}\left(n^{*}\right)
$$

is satisfied. If the payment is supposed to be negative, the second earner makes the relevant decision. For her, we have

(DE2)

$$
-p_{1} \leq \delta(1-\alpha) \bar{s}_{2}\left(n^{*}\right)
$$

However, since the choice of $\alpha$ is part of the HRC, we can focus on arrangements where $p_{1}$ is positive.

In the following, we derive a number of Corollaries that substantially simplify the analysis. The proofs of all of them can be found in the Appendix.

Corollary 1: Without loss of generality, the transfer $p_{1}$ can be positive.

The intuition is that players' risk neutrality makes them indifferent between receiving a transfer today or the same amount (in expectation and discounted) tomorrow. Corollary 1 allows us to omit (DE2). A further simplification is implied by Assumption 3. Because of $\underline{n}_{1}>\underline{n}_{2}$, (IC2) is the only incentive compatibility constraint that actually has to be considered.

Corollary 2: (IC1) can be omitted.

Hence, the only relevant constraints are (IC2) and (DE1). Combining these two conditions gives one constraint that is both necessary and sufficient for an equilibrium fertility level $n^{*}$ to be enforceable.

Corollary 3: A fertility level $n^{*}$ can be enforced if and only if it satisfies the (IC-DE) constraint

$$
\varphi_{2}\left(n^{*}\right)-\varphi_{2}(\underline{n})-w_{21}\left(c\left(n^{*}\right)-c(\underline{n})\right)+\delta \bar{s}_{2}\left(n^{*}\right)+\delta\left(\bar{u}_{22}^{d}\left(n^{*}\right)-\bar{u}_{22}^{d}(\underline{n})\right) \geq 0 .
$$

The (IC-DE) constraint states that gains from deviating today must not exceed the future surplus, i.e. equilibrium payoffs net of reservation utilities. Then, the surplus of remaining together is used to incentivize the secondary earner to agree on a higher fertility level. Corollary 3 also implies that the enforceability of $n^{*}$ is independent of $\alpha$, i.e. the distribution of the future surplus. 
Equivalently to corollary 1, this is driven by the players' indifference towards receiving current or future payments. Furthermore, an exogenous bound on $p_{1}$ (for example induced by borrowing restrictions) would not affect the maximum enforceable fertility level $n^{*}$ : Any bound on $p_{1}$ could simply be offset by a lower $\alpha$.

\subsection{The Maximization Problem}

As stated above, we are interested in the HRC that maximizes the sum of players discounted payoffs, as expected at the beginning of period $t=1$. Formally, this is equivalent to selecting equilibrium fertility $n^{*}$ as well as $m \in\{0,1\}$ to solve

$$
\max \bar{U}_{1}+\bar{U}_{2}=u_{1}(n)+u_{2}(n)+\delta\left(\bar{s}_{2}(n)+\bar{u}_{12}^{d}(n)+\bar{u}_{22}^{d}(n)\right)
$$

subject to the (IC-DE) constraint,

$$
\varphi_{2}\left(n^{*}\right)-\varphi_{2}(\underline{n})-w_{21}\left(c\left(n^{*}\right)-c(\underline{n})\right)+\delta\left(\bar{s}_{2}\left(n^{*}\right)+\bar{u}_{22}^{d}\left(n^{*}\right)-\bar{u}_{22}^{d}(\underline{n})\right) \geq 0
$$

where the (IC-DE) constraint for the case $m=0$ involves setting $k_{1}=k_{2}=\phi=0$. In addition, the technical assumption $n^{*} \leq \bar{n}$ must hold.

\section{Equilibrium Fertility for a Given Choice of $m$}

We now characterize equilibrium fertility and derive comparative statics results with respect to changes in $k_{i}$ and $\phi$. In doing so, we want to contribute to the public discussion on why fertility in (especially) Western countries has been falling. This discussion usually restricts attention to a simple benefit-cost analysis and discusses the effectiveness of several policies to reduce the (direct and indirect) costs of having children. All these issues could also be incorporated into our model, yielding predictable results. ${ }^{17}$ Here, we take a different approach and show that legislation that is not directly aimed at influencing the propensity to have children might have a substantial impact as well.

Divorce laws influence relationship stability and/or the absolute and relative welfare levels of spouses after a separation. Hence, these rules will directly affect each partner's utility as well as the enforceability of transfers, by having an impact on the credibility of punishment threats as well as the risk of being left alone. However, one has to be careful that all this is only true in the short run, i.e. for a given choice of $m$. If a legislative change for example increases fertility but decreases a couple's welfare, incentives to marry go down. Then, the long-run effect of this policy change might ultimately decrease fertility. This issue is further discussed in section 5 below.

\footnotetext{
${ }^{17}$ For example, providing subsidized child-care facilities would reduce $c(n)$ for each $n$ and thus increase fertility.
} 
Now, $n^{*}$ maximizes (4), subject to (IC-DE). If the (IC-DE) constraint does not bind, fertility is at its efficient level.

Lemma 3: If (IC-DE) does not bind, either $n^{*}=\bar{n}$, or the optimal fertility $n^{*}$ satisfies

$$
(1+\delta)\left[\varphi_{1}^{\prime}\left(n^{*}\right)+\varphi_{2}^{\prime}\left(n^{*}\right)\right]=w_{21} c^{\prime}\left(n^{*}\right)-\delta w_{22}^{\prime}\left(n^{*}\right)
$$

Proof: Follows from setting $d\left[u_{11}(n)+u_{12}(n)+\delta\left(\bar{s}_{2}(n)+\bar{u}_{12}^{d}(n)+\bar{u}_{22}^{d}(n)\right)\right] / d n=0$. Q.E.D.

This condition equates the household's marginal benefit of the public good fertility to its marginal costs, which consist of child care costs plus loss of human capital to the second earner. Note that Lemma 3 implies that efficient fertility is the same for cohabiting and married couples. The reason is that in our setting, the only difference between marriage and cohabition is the existence of divorce costs and (post-divorce) alimony payments in the former case. This point is further explored in Lemma 4.

To restrict the number of cases that must be analyzed, we assume that first-best fertility is below $\bar{n}$ :

Assumption 4: The efficient fertility level is characterized by 6 , i.e. $n^{*}<\bar{n}$.

Furthermore, we can show that first-best fertility is independent of post-divorce regulation.

Lemma 4: If (IC-DE) does not bind, neither divorce costs nor alimony payments affect fertility.

Proof: Follows from implicitly differentiating (6). Q.E.D.

Although higher costs $k_{i}$ reduce the likelihood of a divorce, this does not make the couple willing to have more children, simply because the associated utility is the same within and outside the relationship. If the (IC-DE) constraint binds, however, equilibrium fertility $n^{*}$ is determined by the binding (IC-DE) constraint, and the situation changes. Therefore, we first derive conditions under which the constraint actually binds, and then explore comparative statics.

Proposition 1: For $m=0$, there exists a threshold value of the relationship capital, $\bar{R}^{0} \geq 0$, such that (IC-DE) binds for $R<\bar{R}^{0}$ and does not bind-for first-best fertility as described by (6) otherwise. For $m=1$ and $k_{1}+k_{2}$ sufficiently small, there exists a value $\bar{R}^{1} \geq 0$ such that (IC-DE) binds for $R<\bar{R}^{1}$ and does not bind otherwise. Furthermore, $\bar{R}^{1}$ is decreasing in $k_{1}+k_{2}$ and $\phi$. If $k_{1}+k_{2}$ is sufficiently large, (IC-DE) does not bind even for $R=0$. In any case, $\bar{R}^{1} \leq \bar{R}^{0}$. 
The proof can be found in the Appendix.

Hence, it is possible that (IC-DE) binds and restricts enforceable fertility below its first-best level, an issue absent in any collective model. There, conditions regarding the (dynamic) enforcement of transfers within a household are not considered. Furthermore, the (IC-DE) constraint is less likely to bind if the relationship capital $R$ is higher. The reason is that this capital would be lost if an out-equilibrium separation occured. Note that the value $\underline{R}$ - the "betrayed" partner's relationship capital after a defection - does not enter here, because this partner rather induces a separation than "consuming" $\underline{R}$ (see Assumption 2).

A further aspect of Proposition 1 is that higher divorce costs generally relax the (IC-DE) constraint and help to enforce transfers within the household. The reason is the increased relationship stability induced by divorce costs - this stability however comes at the cost of potentially preventing a separation that would actually be optimal, an aspect further analyzed in section 5 below. Alimony payments also help to enforce transfers and hence increase the likelihood that (IC-DE) does not bind. This result is driven by alimony payments triggering an after-divorce redistribution, which (partially) compensates the second earner for her human capital loss.

Finally, because of the monotonicity of $\bar{R}^{1}$ in costs and alimony payments, the (IC-DE) constraint is less likely to bind if the couple is married. A similar mechanism drives the results presented in Lemma 5, where we derive comparative statics for the number of kids if the (IC-DE) constraint (5) binds:

Lemma 5: Assume $m=1$ and $R<\bar{R}^{1}$, i.e. (IC-DE) binds. Then, equilibrium fertility $n^{*}$ is increasing in $k_{i}$ and $\phi$.

The proof to this Lemma can be found in the Appendix.

As higher divorce costs reduce the likelihood of a divorce without decreasing the severity of punishment, the range of states where surplus can be redistributed and used to provide incentives becomes larger. Divorce costs thus serve as a commitment device when (IC-DE) binds - given the couple has chosen $m=1$. This outcome has been supported empirically by Rasul (2005), Stevenson (2007), Matouschek and Rasul (2008), and Bellido and Marcén (2011).

Higher monetary payments partially compensate the second earner for her human capital loss and thus reduce her marginal costs of having children. For a given fertility level the difference between her on- and off-equilibrium fertility increases as $w_{22}(\underline{n})>w_{22}\left(n^{*}\right)$. Thus, more redistribution between the spouses can be enforced, allowing them to increase $n^{*}$. This positive effect of alimony payments on fertility would not appear within a collective model where decisions are efficient by assumption. 


\section{Marriage Versus Cohabitation}

Finally, we analyze the couple's initial decision - whether they want to marry or cohabit - and how it is affected by $k_{i}$ and $\phi$. The partners will opt for a marriage if their utilities then are higher than those they expect from cohabiting. There, recall our assumption that a couple marries if and only if the sum of expected utility streams is higher under marriage. ${ }^{18}$

Since the difference between marriage and cohabitation is entirely driven by institutional differences, a marriage can only be beneficial if divorce costs and alimony payments help to overcome problems associated with too low fertility. Hence, he choice of $m \in\{0,1\}$ crucially depends on whether the (IC-DE) constraint binds for $m=0$. If it does not bind, a marriage will never be optimal:

Proposition 2: Assume $R \geq \bar{R}^{0}$, i.e. the (IC-DE) constraint does not bind for $m=0$. Then, a marriage cannot be optimal if $k_{i}>0$ and $G(\hat{v})<1$. If $k_{i}=0$ or $G(\hat{v})=1$, the couple is indifferent between $m=0$ and $m=1$.

The proof of Proposition 2 can be found in the Appendix.

If fertility is already at its efficient level given $m=0$, the increased commitment induced by divorce costs is not necessary. In addition, these costs reduce the partners' expected utility, since surplus is destroyed when players cannot consume outside utilities $v_{i}$ where it would otherwise be optimal (note that marriage stability has no value per se).

Our analysis would end here if we used a collective model and simply assumed efficient fertility. However, if the (IC-DE) constraint binds, the institutional setting provided by a marriage can help the couple to relax commitment problems that endogenously restrict fertility.

Proposition 3: Assume that $R<\bar{R}^{0}$, i.e. the (IC-DE) constraint binds for $m=0$. Then, a marriage with strictly positive divorce costs is optimal if the relationship per se is sufficiently stable. Moreover, a higher value of $\phi$ always increases the relative benefits of a marriage.

The proof of Proposition 3 can be found in the Appendix.

Whereas post-divorce monetary transfers always increase the couple's tendency to marry if (ICDE) binds, the same is not true for divorce costs, where the couple has to trade off the benefits of an increased commitment with the associated costs of a "too stable" relationship. Interestingly, this implies that couples that are very likely to stay together anyway should be more inclined to also get married - simply because a separation and the associated divorce costs merely are

\footnotetext{
${ }^{18}$ This is equivalent to allowing for transfers when the relationship is formed and its status set.
} 
off-equilibrium phenomena.

The impact of divorce costs on marriage rates has received substantial attention in the empirical literature, mainly due to the replacement of consent with unilateral divorce laws in many US states some decades ago, which is usually regarded as a reduction in divorce costs. ${ }^{19}$ Generally, empirical results are ambiguous. Whereas Rasul (2003) and Matouschek and Rasul (2008) observe a decline, Alesina and Giuliano (2007) on the contrary find an increase of marriage rates. This supports our result that the greater degree of commitment induced by higher divorce costs is not automatically preferred by couples, since post-divorce utilities are reduced as well as the option to utilize high realizations of outside utilities. Only if the utility loss induced by the binding (IC-DE) constraint is sufficiently high can the existence of divorce costs make marriage optimal. If divorce costs are relatively high, their reduction might make more couples willing to use them as a commitment device to increase fertility. Alesina and Guiliano's (2007) results are in line with this interpretation. There, in-wedlock fertility basically remained unaffected by the adoption of unilateral divorce laws, while out-of-wedlock fertility decreased significantly and fertility rates for newly married couples went up. However, to fully understand long-run effects of legal changes on fertility, more empirical evidence is needed.

Finally, we explore the relationship between the couple's tendency to marry and changes in the opportunity costs of having children.

Proposition 4: Assume $R<\bar{R}^{1}$, i.e. (IC-DE) binds for both values of $m$. Furthermore, assume the functional forms $c(n)=C+\gamma n^{j}, j \geq 1$, and $w_{22}(n)=W_{22}-\omega n^{k}, k \geq 1$. Then, the relative benefits of a marriage relative to a cohabitation increase in $\gamma$ and $\omega$.

The proof of Proposition 4 can be found in the Appendix.

This result is driven by the negative impact of higher marginal opportunity costs on enforceable fertility. Given $n^{*}$ is below its first-best level anyway, lower fertility implies a higher marginal utility of children - and consequently larger gains from the additional commitment provided by a marriage. However, note that this result is not as strong as our previous ones. We cannot say whether larger values of $\gamma$ and $\omega$ (as used here) have a positive or negative impact on $\bar{R}^{m}$ - hence on the question whether (IC-DE) binds. The reason is that there are two conflicting forces - on the one hand, higher marginal opportunity costs reduce enforceable fertility, on the other hand they also reduce first-best fertility. Since we do not know which of these dominates, the total effects remains unclear. However, if (IC-DE) binds, higher marginal opportunity costs work in favor of a marriage.

The predictions of Proposition 4 are particularly interesting when it comes to the second earner's

\footnotetext{
${ }^{19}$ This is supported by the fact that divorce rates immediately went up after the introduction of unilateral divorce, see Friedberg (1998) or Matouschek and Rasul (2008).
} 
human capital loss. Generally, we would expect higher educational levels associated with greater human capital losses. A university graduate's future income are very likely to be stronger affected by a timeout than the income of, for example, cleaning personnel or salesclerks. Thus, couples with a better-educated second earner should have a higher propensity to marry given they want to have children. This prediction is well supported by empirical evidence. According to McLanahan (2004) or Lundberg and Pollak (2007), mothers with college education still mostly have their children within a marriage, whereas nonmarital childbearing has substantially gone up for mothers with lower levels of education. There, the latter's reduced propensity to marry might reflect a declining importance of cultural norms fostering marriage. Generally, we have left out such norms in our analysis and hence only capture a limited part of the potential benefits of marriage. For some couples, marriage might have a value per se, ${ }^{20}$ and young adults may still face more or less pressure - arising from social norms and attitudes - to get married rather than cohabit in some societies. However, it seems that a stigma coming from cohabitation or nonmarital childbearing has almost disappeared in most (Western) societies (see Lundberg and Pollak, 2007).

To conclude, recall our assumption that the second earner alone is responsible for raising the couple's children. It seems unlikely that the fact that women still assume major parts of the responsibilities associated with having children is purely driven by an optimal (in an economic sense) allocation of tasks, but could also be influenced by factors outside our model, for example cultural norms and values. If men were willing to participate substantially in child-rearing and if jobs were sufficiently flexible, i.e. if the couple were able to commit to any allocation of childrearing costs $c(n)$, a more efficient time allocation to childcare could be achieved. Then, the (IC-DE) would be less likely to bind and fertility could increase. Therefore, couples with more traditional views on specialization within the household should also be more likely to get married, a claim that is supported by empirical evidence ${ }^{21}$.

\section{Conclusion}

Making precise the conditions under which cooperation within a relationship can be enforced, this paper has shown how the institutional setting following a separation can make it easier or more difficult to allocate resources within a household and thus compensate a partner for the human capital loss associated with having children. However, our approach is only a first step in the analysis of the (often unintended) consequences of legislative choices.

Our model is general enough to incorporate further laws that are important for a marriage. The impact of different forms of income taxation - for example joint versus individual taxation

\footnotetext{
${ }^{20}$ Which could be captured in our model by assuming different values of $R$ for spouses that are cohabiting and those that are married.

${ }^{21}$ Kaufmann (2004) for example finds that men with egalitarian counterparts are more likely to cohabit than those with more traditional views
} 
- could be analyzed. The model is also precise enough to look at the question of consent versus unilateral divorce in more depth. Of course, a unilateral divorce is very likely to be associated with lower divorce costs, as shown by the large empirical literature that found an immediate increase in divorce rates following its introduction. However, noting that under a consent regime one partner alone cannot easily bring about a divorce might allow us to explain some empirical results that cannot be explained by a change in commitment power alone. For example, Alesina and Giuliano (2007) find that after the introduction of unilateral divorce laws, fertility rates for newly married couples increased, while out-of-wedlock fertility decreased. They claim that lower divorce costs induce couples to enter marriage more readily. A model such as ours can provide an explanation: A consent divorce regime taken literally makes it much more difficult to enforce payments between spouses. The reason is that transfers are no longer needed to keep the partner within a marriage, and allocations on and off the equilibrium path do not differ. ${ }^{22}$

The model setting itself could be extended by taking children's welfare into account and adding a thorough analysis of custody arrangements. Halla (2013) provides interesting empirical results showing that the introduction of joint custody in US states increased marriage rates as well as overall fertility. It should be interesting to derive the impact of children's welfare and custody laws on aspects of commitment as analyzed here.

In conclusion, we hope to have shown that an approach to the issues surrounding marriage, fertility and divorce based on the theory of relational contracts can make a new and useful contribution to our understanding of the complex interrelationships among these important institutional features of a modern society.

\footnotetext{
${ }^{22}$ This is even the case if transfers to prevent the inefficient continuation of a marriage are feasible, since such transfers go hand in hand with the ending of the relationship.
} 


\section{Appendix}

Corollary 1: Without loss of generality, the transfer $p_{1}$ can be positive.

Proof: Assume the HRC involves a negative $p_{1}$ and the share $\alpha$. Replacing $p_{1}$ by $\tilde{p}_{1}=0$ and $\alpha$ by $\tilde{\alpha}=\frac{-p_{1}+\delta \alpha \bar{s}_{2}\left(n^{*}\right)}{\delta \bar{s}_{2}\left(n^{*}\right)}$ leaves all constraints and profits as expected at the end of period $t=1$ unaffected. Since $-p_{1} \leq \delta(1-\alpha) \bar{s}_{2}\left(n^{*}\right)$, we still have $\tilde{\alpha} \in[0,1]$. Q.E.D.

Corollary 2: (IC1) can be omitted.

Proof: This follows from $\underline{n}_{1}>\underline{n}_{2}, \underline{n}=\min \left\{\underline{n}_{1}, \underline{n}_{2}\right\}, n^{*} \geq \underline{n}$ and the concavity of $u_{10}^{0}+\delta \bar{u}_{12}^{d}$. Q.E.D.

Corollary 3: A fertility level $n^{*}$ can be enforced if and only if it satisfies the (IC-DE) constraint

$$
\varphi_{2}\left(n^{*}\right)-\varphi_{2}(\underline{n})-w_{21}\left(c\left(n^{*}\right)-c(\underline{n})\right)+\delta \bar{s}_{2}\left(n^{*}\right)+\delta\left(\bar{u}_{22}^{d}\left(n^{*}\right)-\bar{u}_{22}^{d}(\underline{n})\right) \geq 0 .
$$

Proof: Necessity follows from adding (IC2) and (DE1). For sufficiency, assume that 7is satisfied. Set $p_{1}^{+} \equiv \alpha \delta \bar{s}_{2}\left(n^{*}\right)$ and plug it into (IC-DE), which becomes $\varphi_{2}\left(n^{*}\right)-\varphi_{2}(\underline{n})-w_{21}\left(c\left(n^{*}\right)-c(\underline{n})\right)+$ $p_{1}^{+}+\delta(1-\alpha) \bar{s}_{2}\left(n^{*}\right)+\delta\left(\bar{u}_{22}^{d}\left(n^{*}\right)-\bar{u}_{22}^{d}(\underline{n})\right) \geq 0$. Thus, (IC2) is satisfied. Furthermore, (DE1) holds by by construction of $p_{1}^{+}$. Q.E.D.

Proposition 1: For $m=0$, there exists a threshold value of the relationship capital, $\bar{R}^{0} \geq 0$, such that (IC-DE) binds for $R<\bar{R}^{0}$ and does not bind - for first-best fertility as described by (6) otherwise. For $m=1$ and $k_{1}+k_{2}$ sufficiently small, there exists a value $\bar{R}^{1} \geq 0$ such that (IC-DE) binds for $R<\bar{R}^{1}$ and does not bind otherwise. Furthermore, $\bar{R}^{1}$ is decreasing in $k_{1}+k_{2}$ and $\phi$.

If $k_{1}+k_{2}$ is sufficiently large, (IC-DE) does not bind even for $R=0$. In any case, $\bar{R}^{1} \leq \bar{R}^{0}$.

Proof:

The (IC-DE) constraint equals

$$
\begin{aligned}
& \varphi_{2}\left(n^{*}\right)-\varphi_{2}(\underline{n})-w_{21}\left(c\left(n^{*}\right)-c(\underline{n})\right)+\delta \bar{s}_{2}\left(n^{*}\right)+\delta\left(\bar{u}_{22}^{d}\left(n^{*}\right)-\bar{u}_{22}^{d}(\underline{n})\right) \geq 0, \text { where } \\
& \bar{s}_{2}\left(n^{*}\right)=G(\hat{v})\left[u_{12}^{*}\left(n^{*}\right)+u_{22}^{*}\left(n^{*}\right)-\left(\bar{u}_{12}^{d}\left(n^{*} \mid v \leq \hat{v}\right)+\bar{u}_{22}^{d}\left(n^{*} \mid v \leq \hat{v}\right)\right)\right] .
\end{aligned}
$$

Hence, we can rewrite the constraint as

$$
\begin{aligned}
& \varphi_{2}\left(n^{*}\right)-\varphi_{2}(\underline{n})-w_{21}\left(c\left(n^{*}\right)-c(\underline{n})\right)+\delta G(\hat{v})\left[\left(2 R+\mathbf{1}_{m=1}\left\{k_{1}+k_{2}\right\}\right)-\frac{1}{G(\hat{v})} \int_{0}^{\hat{v}} \tilde{v} g(\tilde{v}) d \tilde{v}\right] \\
& +\delta\left[w_{22}\left(n^{*}\right)+\varphi_{2}\left(n^{*}\right)+\mathbf{1}_{m=1}\left\{\phi \cdot\left(w_{1}-w_{22}\left(n^{*}\right)\right)\right\}\right] \\
& -\delta\left[w_{22}(\underline{n})+\varphi_{2}(\underline{n}) \mathbf{1}_{m=1}\left\{\phi \cdot\left(w_{1}-w_{22}(\underline{n})\right)\right\}\right] \geq 0,
\end{aligned}
$$

where $\mathbf{1}_{m=1}$ is the indicator function that includes divorce costs and alimony payments if the couple is married. 
Note that $2 R+\mathbf{1}_{m=1}\left\{k_{1}+k_{2}\right\}=\hat{v}$ and $G(\hat{v})=\int_{0}^{\hat{v}} g(\tilde{v}) d \tilde{v}$.

Hence, $G(\hat{v})\left[\left(2 R+\mathbf{1}_{m=1}\left\{k_{1}+k_{2}\right\}\right)-\frac{1}{G(\hat{v})} \int_{0}^{\hat{v}} \tilde{v} g(\tilde{v}) d \tilde{v}\right]$

$=\hat{v} \int_{0}^{\hat{v}} g(\tilde{v}) d \tilde{v}-\int_{0}^{\hat{v}} \tilde{v} g(\tilde{v}) d \tilde{v}=\int_{0}^{\hat{v}}(\hat{v}-\tilde{v}) g(\tilde{v}) d \tilde{v}$.

Then, (IC-DE) equals

$$
\begin{gathered}
w_{21}\left(c(\underline{n})-c\left(n^{*}\right)\right)+\varphi_{2}\left(n^{*}\right)-\varphi_{2}(\underline{n}) \\
+\delta\left(w_{22}\left(n^{*}\right)+\varphi_{2}\left(n^{*}\right)-w_{22}(\underline{n})-\varphi_{2}(\underline{n})\right) \\
+\delta \int_{0}^{\hat{v}} g(\tilde{v})(\hat{v}-\tilde{v}) d \tilde{v}+\mathbf{1}_{m=1}\left\{\delta \phi\left(w_{22}(\underline{n})-w_{22}\left(n^{*}\right)\right)\right\} \geq 0,
\end{gathered}
$$

Note that $\varphi_{2}(\underline{n})-w_{21} c(\underline{n})+\delta\left(w_{22}(\underline{n})+\varphi_{2}(\underline{n})+\mathbf{1}_{m=1} \phi w_{22}(\underline{n})\right)$

$-\left[\varphi_{2}\left(n^{*}\right)-w_{21} c\left(n^{*}\right)+\delta\left(w_{22}\left(n^{*}\right)+\varphi_{2}\left(n^{*}\right)+\mathbf{1}_{m=1} \phi w_{22}\left(n^{*}\right)\right)\right] \geq 0$ because of $\underline{n}=\underline{n}_{2} \leq n^{*}$ (if this expression were negative, $\underline{n}_{2}$ would not be the second earner's preferred fertility level absent transfers). Hence, the left hand side of (8) without the term $\delta \int_{0}^{\hat{v}} g(\tilde{v})(\hat{v}-\tilde{v}) d \tilde{v}(\geq 0)$ is negative.

Furthermore, since $\hat{v}=2 R+\mathbf{1}_{m=1}\left\{k_{1}+k_{2}\right\}$, the term $\int_{0}^{\hat{v}} g(\tilde{v})(\hat{v}-\tilde{v}) d \tilde{v}-$ and thereby the left hand side of (IC-DE) - increases in $R$. Hence, if $m=0$, there exists a value of $R\left(n^{\#}\right) \geq 0$ for any given fertility level $n^{\#} \geq \underline{n}$ such that (IC-DE) is satisfied for $n^{\#}$. This proves the existence of $\bar{R}^{0}$ (for efficient fertility), as well as the claim that (IC-DE) binds for values of $R$ below $\bar{R}^{0}$ and does not bind for values above. If $m=1$, (IC-DE) might already be satisfied for first-best fertility even if $R=0$, namely when $k_{1}+k_{2}$ is sufficiently large. The reason is that $\hat{v}$ and hence $\int_{0}^{\hat{v}} g(\tilde{v})(\hat{v}-\tilde{v}) d \tilde{v}$ increases in $k_{i}$. Now assume that $k_{1}+k_{2}$ is small enough that (IC-DE) is not satisfied for first-best fertility given $R=0$. The existence of $\bar{R}^{1} \geq 0$ then follows from the same arguments as above, as well as $\frac{d \bar{R}^{1}}{d k_{i}} \leq 0$.

Now, assume that $\bar{R}^{1} \geq 0$ exists. Then, $\frac{d \bar{R}^{1}}{d \phi}=-\frac{\left[(1+\delta) \varphi_{2}^{\prime}(\underline{n})-w_{21} c^{\prime}(\underline{n})+\delta\left(w_{22}^{\prime}(\underline{n})+\phi w_{22}^{\prime}(\underline{n})\right)\right] \frac{d \underline{n}}{d \phi}+\delta\left(w_{22}(\underline{n})-w_{22}\left(n^{*}\right)\right)}{2 \delta G(\hat{v})}$, where however $\left[(1+\delta) \varphi_{2}^{\prime}(\underline{n})-w_{21} c^{\prime}(\underline{n})+\delta\left(w_{22}^{\prime}(\underline{n})+\phi w_{22}^{\prime}(\underline{n})\right)\right]=0$ is the first-order condition determining $\underline{n}$. Because of $w_{22}(\underline{n})-w_{22}\left(n^{*}\right) \geq 0, \frac{d \bar{R}^{1}}{d \phi} \leq 0$ follows. Q.E.D.

Lemma 5: Assume $m=1$ and $R<\bar{R}^{1}$, i.e. (IC-DE) binds. Then, equilibrium fertility $n^{*}$ is increasing in $k_{i}$ and $\phi$.

Proof: The binding (IC-DE) equals 


$$
\begin{gathered}
w_{21}\left(c(\underline{n})-c\left(n^{*}\right)\right)+\varphi_{2}\left(n^{*}\right)-\varphi_{2}(\underline{n}) \\
+\delta\left(w_{22}\left(n^{*}\right)+\varphi_{2}\left(n^{*}\right)-w_{22}(\underline{n})-\varphi_{2}(\underline{n})\right) \\
+\delta \int_{0}^{\hat{v}} g(\tilde{v})(\hat{v}-\tilde{v}) d \tilde{v}+\delta \phi\left(w_{22}(\underline{n})-w_{22}\left(n^{*}\right)\right)=0 .
\end{gathered}
$$

First of all, note that the first partial derivative of the left hand side of (IC-DE) with respect to $n^{*}$, denoted $\partial(I C-D E) / \partial n$, is $-w_{21} c^{\prime}\left(n^{*}\right)+\delta w_{22}^{\prime}\left(n^{*}\right)(1-\phi)+\varphi_{2}^{\prime}\left(n^{*}\right)$ and has to be negative for the (IC-DE) constraint to bind. Otherwise, higher fertility would relax the constraint, contradicting that it binds and fertility is too low at the same time. Since $\frac{d \int_{0}^{\hat{v}} g(\tilde{v})(\hat{v}-\tilde{v}) d \tilde{v}}{d \hat{v}}=G(\hat{v})$ and $\hat{v}=2 R+k_{1}+k_{2}$, we have - as $\underline{n} \leq n^{*}$ :

$$
\begin{aligned}
\frac{d n^{*}}{d k_{i}} & =-\frac{\delta G(\hat{v})}{\partial(I C-D E) / \partial n}>0 \\
\frac{d n^{*}}{d \phi} & =-\delta \frac{\bar{w}_{2}(\underline{n})-\bar{w}_{2}\left(n^{*}\right)}{\partial(I C-D E) / \partial n}>0
\end{aligned}
$$

Q.E.D.

Proposition 2: Assume $R \geq \bar{R}^{0}$, i.e. the (IC-DE) constraint does not bind for $m=0$. Then, a marriage cannot be optimal if $k_{i}>0$ and $G(\hat{v})<1$. If $k_{i}=0$ or $G(\hat{v})=1$, the couple is indifferent between $m=0$ and $m=1$.

Proof: The couple is getting married if and only if $\bar{U}_{1}(m=1)+\bar{U}_{2}(m=1)$

$\geq \bar{U}_{1}(m=0)+\bar{U}_{2}(m=0)$. Since $n^{*}$ is at its efficient level, applying the Envelope Theorem gives

$$
\begin{gathered}
\frac{d\left(\bar{U}_{1}+\bar{U}_{2}\right)}{d k_{i}}=\frac{\partial\left(\bar{U}_{1}+\bar{U}_{2}\right)}{\partial k_{i}}=-\delta[1-G(\hat{v})] \leq 0 \\
\frac{d\left(\bar{U}_{1}+\bar{U}_{2}\right)}{d \phi}=\frac{\partial\left(\bar{U}_{1}+\bar{U}_{2}\right)}{\partial \phi}=0 .
\end{gathered}
$$

The monotonicity of $\bar{U}_{1}+\bar{U}_{2}$ implies that a positive value of $k_{i}$ is always worse than having $k_{i}=0$, which is the case for $m=0$. Q.E.D.

Proposition 3: Assume that $R<\bar{R}^{0}$, i.e. the (IC-DE) constraint binds for $m=0$. Then, 
a marriage with strictly positive divorce costs is optimal if the relationship per se is sufficiently stable. Moreover, a higher value of $\phi$ always increases the relative benefits of a marriage.

Proof: Assume divorce costs are $k_{i}^{*}$, and the alimony parameter is $\phi^{*}$.

$$
\begin{aligned}
& \text { Then, } \bar{U}_{1}(m=1)+\bar{U}_{2}(m=1)-\left[\bar{U}_{1}(m=0)+\bar{U}_{2}(m=0)\right] \\
& =\int_{0}^{k_{1}^{*}} \frac{d\left(\bar{U}_{1}+\bar{U}_{2}\right)}{d k_{1}} d k_{1}+\int_{0}^{k_{2}^{*}} \frac{d\left(\bar{U}_{1}+\bar{U}_{2}\right)}{d k_{2}} d k_{2}+\int_{0}^{\phi^{*}} \frac{d\left(\bar{U}_{1}+\bar{U}_{2}\right)}{d \phi} d \phi, \text { with } \\
& \quad \frac{d\left(\bar{U}_{1}+\bar{U}_{2}\right)}{d k_{i}}=\frac{\partial\left(\bar{U}_{1}+\bar{U}_{2}\right)}{\partial n} \frac{\partial n^{*}}{\partial k_{i}}+\frac{\partial\left(\bar{U}_{1}+\bar{U}_{2}\right)}{\partial k_{i}}=\frac{\partial\left(\bar{U}_{1}+\bar{U}_{2}\right)}{\partial n} \frac{\partial n^{*}}{\partial k_{i}}-\delta(1-G(\hat{v})) \\
& \frac{d\left(\bar{U}_{1}+\bar{U}_{2}\right)}{d \phi}=\frac{\partial\left(\bar{U}_{1}+\bar{U}_{2}\right)}{\partial n} \frac{\partial n^{*}}{\partial \phi}+\frac{\partial\left(\bar{U}_{1}+\bar{U}_{2}\right)}{\partial \phi}=\frac{\partial\left(\bar{U}_{1}+\bar{U}_{2}\right)}{\partial n} \frac{\partial n^{*}}{\partial \phi}>0
\end{aligned}
$$

Since fertility is inefficiently low, $\partial U\left(n^{*}\right) / \partial n>0$. Therefore, it is already proven that a higher value of $\phi$ always increases the relative benefits of a marriage as long as (IC-DE) binds. Furthermore, as long as $G(\hat{v})$ is sufficiently close to 1 , i.e. the relationship is sufficiently stable anyway (absent divorce costs), we will have $\frac{\partial\left(\bar{U}_{1}+\bar{U}_{2}\right)}{\partial n} \frac{\partial n^{*}}{\partial k_{i}}>\delta(1-G(\hat{v}))$. Hence, there is a range of divorce costs where a marriage is optimal. Q.E.D.

Proposition 4: Assume $R<\bar{R}^{1}$, i.e. (IC-DE) binds for both values of $m$. Furthermore, assume the functional forms $c(n)=C+\gamma n^{j}, j \geq 1$, and $w_{22}(n)=W_{22}-\omega n^{k}, k \geq 1$. Then, the relative benefits of a marriage relative to a cohabitation increase in $\gamma$ and $\omega$.

Proof: Note that for a given fertility level $n^{*}$, neither $\gamma$ nor $\omega$ have an impact on the couple's optimal choice of $m$. The reason is that none of them affects the likelihood of a separation. Hence, $\gamma$ or $\omega$ might only affect the couple's choice of $m$ via its impact on enforceable fertility. Therefore, we first show that - if (IC-DE) binds - $\frac{\partial n^{*}}{\partial \gamma}, \frac{\partial n^{*}}{\partial \omega}<0$.

There, recall that the first derivation of the left hand side of the (IC-DE) constraint with respect to $\underline{n}$ is identical to the first-order condition characterising $\underline{n}$. Hence, we do not have to consider the impact of $\gamma$ and $\omega$ on $\underline{n}$.

Then, implicitly differentiating the binding (IC-DE) constraint (8) gives

$$
\begin{aligned}
\frac{\partial n^{*}}{\partial \gamma} & =-\frac{\left[w_{21}\left(\frac{(n)^{j}}{2}-\frac{\left(n^{*}\right)^{j}}{2}\right)\right]}{-w_{21} c^{\prime}\left(n^{*}\right)+\varphi_{2}^{\prime}\left(n^{*}\right)+\delta\left(w_{22}^{\prime}\left(n^{*}\right)+\varphi_{2}^{\prime}\left(n^{*}\right)\right)-\mathbf{1}_{m=1}\left\{\delta \phi w_{22}^{\prime}\left(n^{*}\right)\right\}} \text { and } \\
\frac{\partial n^{*}}{\partial \omega} & =-\frac{\left[\delta\left(-\frac{\left(n^{*}\right)^{k}}{2}+\frac{(n))^{k}}{2}\right)+\mathbf{1}_{m=1}\left\{\delta \phi\left(-\frac{(n)}{2}+\frac{\left(n^{*}\right)^{k}}{2}\right)\right\}\right]}{-w_{21} c^{\prime}\left(n^{*}\right)+\varphi_{2}^{\prime}\left(n^{*}\right)+\delta\left(w_{22}^{\prime}\left(n^{*}\right)+\varphi_{2}^{\prime}\left(n^{*}\right)\right)-\mathbf{1}_{m=1}\left\{\delta \phi w_{22}^{\prime}\left(n^{*}\right)\right\}} \text {. Note that the denominator in both }
\end{aligned}
$$
expressions must be negative - if it were not negative, $\underline{n}\left(<n^{*}\right)$ would not be the second earner's preferred off-equilibrium fertility level. $\frac{\partial n^{*}}{\partial \gamma}<0$ as well as $\frac{\partial n^{*}}{\partial \omega}<0$ then follows from $n^{*}>\underline{n}$, $\phi \leq 0.5$ and $j, k \geq 1$. 
The negative impact of $\gamma$ and $\omega$ on $n^{*}$ implies that the marginal utility of children goes up; there, note that first-best fertility - which is negatively affected by an increase in $\gamma$ or $\omega$ - is not relevant as long as fertility is too low anyway. Hence, the positive impact of a marriage on enforceable fertility is worth more if $\gamma$ and $\omega$ are higher. Q.E.D.

\section{References}

[1] Abreu, Dilip, "Extremal Equilibria of Oligopolistic Supergames," Journal of Economic Theory, 39 (1986), 191-235.

[2] Ahn, Namkee, and Pedro Mira, "A Note on the Changing Relationship Between Fertility and Female Employment Rates in Developed Countries," Journal of Population Economics, 15 (2002), 667-682.

[3] Alesina, Alberta F., and Paola Giuliano, "Divorce, Fertility and the Value of Marriage," Harvard Institute of Economic Research Discussion Paper No. 2136, 2007.

[4] Allen, Douglas W., and Margaret Brinig, "Child Support Guidelines and Divorce Incentives," mimeo, Simon Fraser University and University of Notre Dame, 2010.

[5] Apps, Patricia, and Ray Rees, Public Economics and the Household, Cambridge University Press, 2009.

[6] Becker, Gary S., A Treatise on the Family, Harvard University Press, 1991.

[7] Bellido, Héctor, and Miriam Marcén, "Divorce Laws and Fertility Decisions," MPRA Paper No. 30243, 2011.

[8] Bradshaw, Jonathan, and Naomi Finch, "A Comparison of Child Benefit Packages in 22 Countries," Research Report No. 174, London: Department for Work and Pensions, 2002.

[9] Browning, Martin, and Pierre-André Chiappori, "Efficient Intra-Household Allocation: a Characterisation and Tests," Econometrica, 66 (1998), 1241-1278.

[10] Bull, Clive , "The Existence of Self-Enforcing Implicit Contract," Quarterly Journal of Economics, 102 (1987), 147-159.

[11] Chiappori, Pierre-André, "Collective Labor Supply and Welfare," Journal of Political Ecnomy, 100 (1995), 437-467.

[12] Clark, Simon, "Law, Property, and Marital Dissolution," The Economic Journal, 109 (1999), 41-54. 
[13] Fahn, Matthias, and Ray Rees, "Household Relational Contracts for Marriage, Fertility, and Divorce", Cesifo working paper No. 3655, 2011.

[14] Friedberg, Leora, "Did Unilateral Divorce Raise Divorce Rates? Evidence from Panel Data," American Economic Review, 88 (1998), 608-627.

[15] Halla, Martin, "The Effect of Joint Custody on Family Outcomes," Journal of the European Economic Association, 11 (2013), 278-315.

[16] Hart, Oliver, and John Moore, "Contracts as Reference Points," The Quarterly Journal of Economics, 123 (2008), 1-48.

[17] Immervoll, Herwig, Henrik J. Kleven, Claus T. Kreiner, and Nicolaj Verdelin, "An Evaluation of the Tax-Transfer Treatment of Married Couples in European Countries," , IZA Discussion Paper No. 3965, 2009.

[18] Kaufman, Gayle, "Do Gender Role Attitudes Matter? Family Formation And Dissolution Among Traditional And Egalitarian Men And Women," in Readings In Family Theory, SAGE Publications, 225-236, 2004.

[19] Konrad, Kai A., and Kjell E. Lommerud, "The Bargaining Family Revisited," Canadian Journal of Economics, 33 (2000), 471-487.

[20] Levin, Jonathan, "Relational Incentive Contracts," American Economic Review, 93 (2003), 835-856.

[21] Lundberg, Shelly, and Robert A. Pollak, "Separate Spheres Bargaining and the Marriage Market," Journal of Political Economy, 101 (1993), 988-1010.

[22] Lundberg, Shelly, and Robert A. Pollak, "Efficiency in Marriage," Review of Economics of the Household, 1 (2003), 153-168.

[23] Lundberg, Shelly, and Robert A. Pollak, "The American Family and Family Economics," The Journal of Economic Perspectives, 21 (2007), 3-26.

[24] McElroy, Marjorie B., and Mary J. Horney, "Nash-Bargained Household Decisions Making: Toward a Generalization of the Theory of Demand," International Economic Review, 22 (1981), 333-350.

[25] MacLeod, Bentley W., and James M. Malcomson, "Implicit Contracts, Incentive Compatibility and Involuntary Unemployment," Econometrica, 57 (1989), 447-480.

[26] Manser, Marylin, and Murray Brown, "Marriage and Household Decision Making: a Bargaining Analysis," International Economic Review, 21 (1980), 31-44. 
[27] Matouschek, Niko, and Imran Rasul, "The Economics of the Marriage Contract: Theories and Evidence," Journal of Law and Economics, 51 (2008), 59-110.

[28] McLanahan, Sara, "Diverging Destinies: How Children Are Faring under the Second Demographic Transition," Demography, 41 (2004), 607-27.

[29] Ott, Notburga, Intrafamily Bargaining and Household Decisions. Berlin: Springer-Verlag, 1992.

[30] Peters, H. Elizabeth, "Marriage and Divorce: Informational Constraints and Private Contracting," The American Economic Review, 76 (1986), 437-454.

[31] Rasul, Imran, "The Impact of Divorce Laws on Marriage," mimeo, University of Chicago and CEPR, 2003.

[32] Rasul, Imran, "Household Bargaining over Fertility: Theory and Evidence from Malaysia," Journal of Development Economics, 86 (2008), 215-241.

[33] Rowthorn, Robert, "Marriage and trust: some lessons from economics," Cambridge Journal of Economics, 23 (1999), 661-691.

[34] Schmidt, Klaus M., and Monika Schnitzer, "The Interaction of Explicit and Implicit Contracts," Economics Letters, 48 (1995), 193-199.

[35] Stevenson, Betsey, "The Impact of Divorce Laws on Marriage-Specific Capital," Journal of Labor Economics, 25 (2007), 75-94.

[36] Stevenson, Betsey, and Justin Wolfers, "Marriage and Divorce: Changes and their Driving Forces,“ Journal of Economic Perspectives, 21 (2007), 27-52.

[37] Ulph, David T. "A General Non-Cooperative Nash Model of Household Consumption Behaviour." Working paper 88-205, Department of Economics, University of Bristol, 1988.

[38] Wickelgren, Abraham L., "Why Divorce Laws Matter: Incentives for Non-Contractible Marital Investments under Unilateral and Consent Divorce," Journal of Law, Economics $\&$ Organization, 25 (2009), 80-106.

[39] Wolfers, Justin, "Did Unilateral Divorce Raise Divorce Rates? A Reconciliation and New Results," American Economic Review, 96 (2006), 1802-1820.

[40] Woolley, Frances, "A Non-Cooperative Model of Family Decision Making," TIDI Working Paper 125, London School of Economics, 1988. 